\title{
El cielo y el infierno está aquí: Las culturas populares y el desafío de la gestión
}

\author{
Heaven and hell are here: \\ Popular cultures and the challenge of management
}

\section{Gustavo Remedi*}

\footnotetext{
* Doctor en Literatura Hispanoamericana y Estudios Comparados de Sociedades y Discursos por la Universidad de Minnesota, en Minneapolis. Profesor titular de Teoría y Metodología Literaria (docente grado 5) en la Facultad de Humanidades y Ciencias de la Educación, Universidad de la República, Uruguay.

$\bowtie$ gremedi2@gmail.com
}

RECIBIDO: [19.3.2018]

ACEPTADO: [20.4.2018]

\section{Resumen}

Además de realizar una intervención teórica sobre el concepto de cultura popular —noción siempre escurridiza, relacional, problemática-, en este ensayo exploramos una serie de cuestiones teóricas y de proposiciones relativas al problema adicional de la gestión cultural y, más específicamente, de la gestión de la esfera pública popular o plebeya. Dicha reflexión se organiza y desarrolla en torno a tres aspectos o ejes: a) la cuestión de la esfera pública popular, pensada desde la perspectiva de las prácticas y producciones culturales populares; b) las industrias culturales y los medios masivos, como una de las condiciones de la cultura popular contemporánea; c) el acceso popular, masivo, a los bienes y prácticas culturales, pensado tanto desde la noción de consumo como de su contracara, la recepción productiva. Asimismo, el ensayo descansa sobre la idea de la gestión como un hacer situado (en una cultura y una circunstancia histórica y social), posicionado (que toma partido) y orientado por un proyecto social y cultural. Así, más que repetir el gesto de desagrado y de rechazo típicos de la cultura letrada hacia la cultura de masas y la cultura popular, o su opuesto, el gesto de ingenuo y desmedido entusiasmo, nos mueve el propósito de argumentar en 
favor y desarrollar una gestión orientada hacia la democratización y la transformación social.

Palabras clave: cultura de masas, industria cultural, gestión cultural.

\begin{abstract}
Apart from a theoretical intervention on the concept of popular culture - always an elusive, relational, problematic concept - this essay explores a series of theoretical questions and propositions related to the additional problem of cultural management, and more specifically, to the management of the plebeian or popular public sphere. This reflection is organized and developed along three aspects: a) the issue of the popular public sphere, thought from the perspective of popular cultural practices and productions, b) the cultural industries and the mass media, as one of the conditions of contemporary popular culture, c) popular, massive access to cultural goods and practices, both from the perspective of consumption as well as from its counterpart, or productive reception. Likewise, the essay rests on the idea of cultural management as situated (in a culture with a historical and social background), positioned (that is, it takes sides), and oriented and guided by a social and cultural project. Thus, rather than repeat the gesture of distaste and rejection typical of the lettered culture towards mass culture and popular culture, or its opposite, the gesture of naive and unbridled enthusiasm, the aim is to argue in favor and to develop a managerial strategy concerned with democratization and social transformation.
\end{abstract}

Keywords: mass culture, cultural industry, cultural management.

\title{
Introducción
}

«sí, sí, pero el cielo y el infierno está aquí».

Y lo clavó con esa n que faltaba.

Blas de Otero, Palabra viva y de repente

A la dificultad que ya de por sí conllevan el concepto y la problemática de la cultura popular, asunto respecto del cual intentaremos realizar una intervención teórica, interesa aquí compartir una serie de reflexiones acerca del problema adicional de la gestión cultural y, más específicamente, de la gestión de la esfera pública popular o plebeya.

La cuestión puede a su vez descomponerse y pensarse a lo largo de tres ejes: 
a. la esfera pública popular pensada desde el ángulo de las prácticas y producciones culturales populares;

b. las industrias culturales y los medios masivos, al decir de Martín Barbero (1987), una de las condiciones de la cultura popular contemporánea;

c. el acceso popular, masivo, a los bienes y prácticas culturales, pensado tanto desde la noción de consumo como de su contracara, la recepción productiva.

Por otra parte, como se desprende de estas reflexiones, tampoco es posible pensar en la gestión de un modo abstracto, técnico o neutral. La gestión supone un hacer situado (en una cultura y circunstancia histórica y social), posicionado (que toma partido) y orientado por un proyecto social y cultural. Algo de esto entiendo que quiso decir Benjamin (2004) cuando habló del artista o del autor «como productor». Así, no serán los mismos los parámetros y objetivos de gestión de una empresa cultural con ánimo de lucro o del agregado cultural de un gobierno extranjero que los de una gestión orientada hacia la democratización y la transformación social.

\section{Las dos caras de la gestión}

El caso del teatro de carnaval — una de nuestras formas de teatro popular- quizá sirva para entrar rápidamente en tema e ilustrar dos ángulos distintos y hasta opuestos del problema de la gestión de la cultura, y en particular de la cultura popular.

Desde un punto de vista, asociamos gestión a la idea de gestar algo, concretarlo, hacerlo bien. En el caso del carnaval: la capacidad de inventar y organizar conjuntos, conocer la historia y las reglas del campo, diría Bourdieu (1980), obtener todos los recursos materiales, coordinar un equipo de creadores, saber manejar un grupo desde el punto de vista vincular, lograr salir en carnaval y hacerse presente en los tablados, alcanzar crecientes grados de complejidad artística, profesionalismo y excelencia (no necesariamente reñidos con la tradición del teatro de carnaval). También, de construir y llegar a nuevos públicos, ya sea mediante la multiplicación de escenarios populares o a través de los medios (la radio, el disco, la tele), o de reinventarse y proyectarse incluso más allá del ámbito del concurso y del tiempo de carnaval y tener la posibilidad de intervenir en la realidad nacional y en la propia construcción de sí. En este sentido, gestión significa generar algo y hacerlo bien.

Por contrapartida, la idea de la gestión del carnaval cobra un significado distinto cuando pensamos en los constreñimientos excesivos del Concurso y del Reglamento, que buscan disciplinar y civilizar al carnaval, ya en aras de la lógica de la organización del espectáculo, de los criterios para el otorgamiento de premios, de autorizar o no la participación de los conjuntos en los tablados, o como un intento de subordinar la 
lógica inversa (imaginaria, utópica, irreverente) del carnaval a las leyes del mundo real, a los cánones del arte culto (según la distinción inventada por la Ilustración en la era burguesa). En este sentido, la palabra gestión deja traslucir su lado siniestro: empieza a parecerse a querer controlar, gerenciar, administrar y manejar el carnaval, hacerlo parecerse y duplicar la realidad, de una manera contraria a «la visión carnavalesca del mundo y de la vida» —en los términos de Bajtín $(1987,1993)$ — o a la propia definición y sentido del arte.

La idea de la gestión también preocupa cuando pensamos en los esfuerzos algunos concretados, otros fallidos- por domesticar o manipular el carnaval en uno y otro sentido por parte de distintos actores: las autoridades estatales, los financistas y auspiciantes, las agremiaciones (como DAECPU, AGADU), los medios de comunicación (el caso del poderoso Tenfield es el más notorio, pero no el único).

El ejemplo del carnaval ilustra entonces tanto la importancia de la gestión para las actividades culturales complejas como los temores y rechazos que despierta, sobre todo cuando, en vez de ser un instrumento para potenciar la creación y sus efectos emancipadores, deviene en uno de sometimiento, dominación y manipulación en función de distintos intereses (Horkheimer y Adorno, 1998; Horkheimer, 1973).

\section{Hacia un concepto operativo de gestión cultural}

Por concepto operativo entiendo un concepto precario y entre comillas - es decir, inestable y siempre sospechoso- que de todos modos puede servir de punto de entrada para empezar a plantear una problemática, recorrer una historia y un proceso, y desplegar una serie de consideraciones, inquietudes y dilemas teóricos y prácticos.

Aunque el término haya ganado cierta notoriedad e incluso hoy suene a moda —o a desviación tecnocrática, mercantil, empresarial—, la gestión cultural ha existido toda la vida.

Unas veces, la gestión ha sido realizada por los propios creadores, cuando por ejemplo deben conseguir recursos para producir o exhibir su arte, publicitar y promocionar sus obras, encontrarles públicos o compradores, formar y mantener un grupo, etcétera. Este puede ser el caso del director de una pequeña compañía de teatro, de un colectivo de artistas plásticos, de una banda de música o de un escritor.

Otras veces, estas y otras tareas similares han recaído sobre empresarios o agentes culturales, de diverso tamaño y poderío, que ya por vocación, ya como forma de ganarse la vida, realizan distintas tareas que uno asocia a la gestión: producción, financiación, organización, intermediación, promoción, lidiar con aspectos legales, etcétera. Carlos Quijano y Marcha, Manuel Martínez Carril y Cinemateca Uruguaya, Ronald Melzer y Videoimagen, Heber Raviolo y Ediciones de la Banda Oriental pueden ser pensa- 
dos como gestores culturales que de manera autodidacta y con habilidades adquiridas sobre la experiencia consiguieron incursionar, hacerse un lugar y sobresalir en un territorio dominado por las grandes industrias culturales de la prensa escrita, el cine o el libro.

La organización y puesta en funcionamiento de revistas y periódicos cooperativos como La Diaria, una radioestación comunitaria como El Puente de La Teja o una fiesta tradicional como la de la Patria Gaucha son otros ejemplos de labores y productos de gestión cultural eficaz.

En ocasiones las tareas de gestión también recaen sobre funcionarios públicos a cargo de dependencias y organismos estatales: bibliotecas, museos, salas de espectáculos, elencos artísticos, editoriales, etcétera.

Así como hay instituciones privadas y públicas, locales y nacionales, grandes, medianas y pequeñas, también las hay extranjeras: públicas — como pueden ser el Centro Cultural España o el Instituto Goethe- y privadas - como el Grupo Editorial Planeta, el sello Sony Music o Direct TV— que también realizan trabajos de mediación y gestión cultural.

Otras veces, la gestión supone niveles y tareas todavía más abstractos, como pueden ser la legislación en materia de cultura, el desarrollo de metas, estrategias y políticas culturales (generales o específicas para cada campo de la cultura y el arte), motivadas y alineadas con objetivos de diversa índole: política, geopolítica, económica, financiera, etcétera.

Así, vista desde una perspectiva, la gestión puede significar tomar en cuenta y llevar a cabo toda la serie de tareas que hacen posible una actividad cultural dentro de un determinado campo, conseguir todo lo necesario para que tengan lugar ciertos acontecimientos y procesos culturales, promover tal o cual disciplina, corriente o movimiento cultural, incluido el desarrollo de capacidades de producción cultural a una escala industrial, más compleja, más masiva, con grados crecientes de utilización de tecnología, etcétera, como puede ser estar a cargo un centro cultural, un sello musical, una plataforma mediática o un canal de televisión.

La gestión implicará no solo la investigación y el conocimiento de un campo cultural específico sino, además, el desarrollo de un saber hacer organizacional que permita la realización efectiva de una actividad en grados de excelencia y de ajuste máximo a los objetivos imaginados. Pero también de una capacidad de filosofar, es decir, hacerse las grandes preguntas, pensar la cultura como un fenómeno histórico, global y complejo, desarrollar capacidades de reflexión crítica que habiliten el cuestionamiento de los lineamientos, finalidades, premisas, prejuicios, hábitos y horizontes heredados y naturalizados.

Dicho esto, afirmábamos, la gestión también es asociada a otras nociones y problemas tales como el aprovechamiento económico del quehacer cultural —en el peor 
escenario, la subordinación de la cultura a los intereses económicos- o el gerenciamiento de la cultura con criterios y modos tecnocráticos y burocráticos que surgen del modo de funcionamiento las instituciones y los distintos aparatos culturales (Althusser, 1988). Peor: la administración y el control cultural como forma de ingeniería social, cultural y política en el marco de una batalla cultural (Hall, 1984a), esto es, de una lucha política a través de la cultura (las ideas, los valores, las formas de entender el mundo y la vida, los comportamientos, el lenguaje, la actividad artística, etcétera).

Esa relación entre cultura y poder es todavía más evidente en lo que concierne a la cultura popular, debido tanto a su carácter subalterno (es un efecto de un poder, de un orden cultural tradicional, establecido) como al hecho de que existe como diferencia, desviación o contraste con la cultura oficial (Gramsci, 1986).

Si en el pasado la gestión estaba en manos de un puñado de empresarios y funcionarios, muchos de ellos aficionados, la extensión sin precedentes del campo cultural en el siglo XX, multiplicada por la proliferación de disciplinas, movidas, medios y soportes, sumada a la centralidad y ubicuidad de la cultura en la sociedad contemporánea, donde ya no es tan fácil distinguir y separar el trabajo del tiempo libre, el espacio público del privado e íntimo, la alta de la baja cultura, el consumo de la producción, ha resultado en la necesidad de contar con un personal cada vez más amplio y con mayores capacidades y saberes.

Así surgieron los primeros cursos de capacitación y diplomas en gestión cultural, primero ofrecidos por academias o instituciones privadas (Fundación Banco de Boston, BIOS), y más recientemente carreras y diplomas en gestión universitarios, de grado y posgrado (Espacio Interdisciplinario-UDELAR, Facultad de la Cultura del CLAEH, entre otros).

\section{El problema de la cultura popular}

Si la gestión de la cultura nos muestra ya de por sí una dificultad y una ambivalencia, la cultura popular representa un desafío aún mayor.

Numerosos autores se han ocupado de pensar la cultura popular, de estudiarla y también de cuestionar la noción y sus usos.

Podemos pensar en algunos autores clásicos, como Gramsci, Bajtín, Adorno, Horkheimer, Marcuse, Benjamin y Habermas (desde el Instituto de Investigaciones Sociales de la Universidad de Frankfurt), Hoggart, Williams, Thompson y Hall (en el Centro de Estudios Culturales de la Universidad de Birmingham), los historiadores británicos de la historia desde abajo (Hobsbawm, Scott), Ginzburg, Eco, De Certeau, etcétera. Más cercanos a la región y en el tiempo, los aportes de Rama, Sarlo, Laclau, 
Martín Barbero, García Canclini, los Estudios Subalternos Latinoamericanos (tributarios de los indios), Badiou y Ranciere, Lienhard, Alabarces o Semán, entre otros.

De estas lecturas lo primero que surge es la imposibilidad o futilidad —el errorde intentar definir un concepto estable de cultura popular, de identificar y pensar lo popular - y la cultura popular - de una manera positiva, esencial, unívoca, monolítica, inmutable. En realidad, la cuestión de la cultura popular apenas sirve como un lugar heurístico desde el cual repensar un conjunto de espacios sociales, prácticas, instituciones y procesos culturales, asociados, a su vez, a otras cuestiones: sociales, económicas, estéticas y, fundamentalmente, políticas.

Contra lo que Derrida (1998) denominó la metafísica de la presencia, una y otra vez - estos autores nos advierten-, lo mismo que con el pueblo y todo lo popular, la cultura popular es relacional, situacional, movediza, heterogénea, contradictoria. Nada es en sí y de por sí popular. Lo que ayer fue hoy ya no lo es, o viceversa. No es una sola cosa sino muchas: un conglomerado indigesto, llegó a decir Gramsci en «Observaciones sobre el folclore» (1986).

Como cualquier campo de la cultura, está constituido y atravesado por toda clase de dimensiones y tensiones contradictorias, polaridades irreconciliables, líneas de fuga hacia adelante y hacia atrás, que en unos casos reproducen la dominación, en otros la confrontan y en otros producen estados intermedios o negociados, que no son ni una aceptación total ni un cuestionamiento absoluto, pero que de todas formas son algo nuevo y distinto a lo que existía previamente (Hall, 1984b).

Su estudio debe siempre ser contextual, procesual, relacional y político (Hall, 1984a). Puesto que se trata de un ámbito en condición de subalternidad, no determina las reglas del campo ni la estrategia (De Certeau, 2000). Esto no significa que sea incapaz de desvío, de originalidad acotada, de lenta y silenciosamente modificar las reglas y torcer rumbos (ni los gustos y valores estéticos ni los reglamentos en apariencia más férreos permanecen inmutables en el tiempo), de producir gérmenes de una cultura alternativa a la realidad establecida, a una visión de mundo oficial, a la cultura hegemónica.

Decir que es procesual, contextual, relacional significa que desde el punto de vista analítico y político representa un momento o un polo de una cuestión cultural dinámica, que se define en relación con su opuesto (el poder), en un juego donde ni un término ni el otro son estables ni monolíticos, sino que se mueven, mutan, cambian su sentido, valor, posición y función, afectados por contextos y circunstancias concretas. De aquí la necesidad de captar la dinámica que lo moviliza y las constantes reconfiguraciones del campo; las claves para su comprensión son coyunturales, histórica y geográficamente específicas, etcétera. 


\section{Esfera pública popular y transculturadores populares}

Como resultado de lo anterior, para no perder de vista dicha complejidad, sostenemos la conveniencia de echar mano de la noción de esfera pública popular, tributaria de la noción de esfera pública.

La esfera pública burguesa, según Habermas (1981), surge en una determinada coyuntura histórica: la segunda Modernidad europea, el siglo XVIII. Supuso una serie de medios (el lenguaje escrito, la letra impresa, las editoriales, los periódicos y revistas literarias), un ámbito de sociabilidad (los cafés, sociedades literarias, clubes sociales) y una serie de principios (la libertad de pensamiento, expresión, reunión y asociación, la argumentación racional, la igualdad y los derechos de los individuos), de los que se sirvió una clase social emergente (la burguesía) para confrontar al poder establecido (la monarquía, la nobleza, la Iglesia), mediar entre el individuo, la sociedad civil y el Estado, y también para contener, cooptar e imponerse a las clases populares (J. B. Thompson, 1996).

Como han propuesto algunos historiadores británicos (especialmente E.P. Thompson, 1989, pero también James Scott (2000) y otros), en relación de diferencia y oposición, tanto a los poderes tradicionales (nobleza, Iglesia) como emergentes (burguesía), históricamente también tuvo lugar una experiencia diferencial de las clases populares (excluida de las ámbitos de la burguesía y que no gozó de los derechos de esta), que se forjó de la mano del surgimiento de otra serie de instituciones, modos pensar y de sentir, espacios de sociabilidad, prácticas, lenguajes y medios, y que resultó en la constitución de una esfera pública aparte, otra, popular o plebeya (si bien nunca aislada, ni inconexa, ni homogénea, ni pensable sin tomar en cuenta las condiciones de exclusión y subordinación respecto a las clases dominantes).

Aparte de su carácter relacional, la esfera pública popular tiene, sin embargo, algunos rasgos singulares que uno puede visualizar pensando, por ejemplo, en los casos del teatro popular, la prensa obrera, el folclore y, hoy en día, las radios comunitarias, el hip hop o los youtubers. El principal de estos rasgos es su accesibilidad a las clases populares tanto desde el punto de vista del consumo (a través de lo cual, aun si en parte, ejercen una demanda y una presión) como de la producción propia (y desde allí la interpelación e intervención en las otras esferas). Como se argumentará, la propia cultura de masas puede también quedar abarcada dentro de la esfera pública popular (contraintuitivamente) una vez que la pensamos desde la recepción.

Igualmente productivo resulta pensar en la noción de transculturación propuesta por Ángel Rama (1982), en cuanto ajuste del concepto de Fernando Ortiz y en su caso aplicada a los escritores, para visualizar en nuestro caso la labor de los transculturadores 
populares: aquellos actores culturales que se desempeñan en la esfera pública popular (aunque no de manera exclusiva, necesariamente) realizando la labor transculturadora de selección y combinación de elementos (lenguajes, formas, símbolos, visiones de mundo, etcétera) provenientes de distintos mundos (alta y baja cultura, cultura letrada y mediática, lo local y lo global, etcétera) y de traducción de todo ello a los términos y las formas de la esfera pública popular.

Así, si bien no pretendemos resolver tan fácilmente el problema de la cultura popular, este apretado repaso sí sirve para evitar una serie de trampas e ilusiones que suelen venir asociadas a la noción de cultura popular de corte romántico, esencialista, populista, positivo, estático, sacada de su contexto, despolitizada, etcétera (García Canclini, 1981, 1986).

\section{Las industrias culturales y los medios masivos}

Tras la aparición de las masas urbanas y de los nuevos medios de comunicación (los periódicos, los folletines, las novelas) desde mediados del siglo XIX y sobre todo en el siglo xx (con la radio, la fotografía, el cine, la tele, internet), lo popular, antes pensado con relación a la vida de la comarca, a la cultura campesina y obrera, a las fiestas pueblerinas tradicionales, ya no sería lo mismo (Martín Barbero, 1987).

Este es a la vez el temor y la fascinación que la cultura popular despierta en pensadores tan diversos como Gramsci, Adorno, Benjamin, Hoggart o Williams, atentos a esta transformación cuantitativa y cualitativa de lo popular, lo mismo que a su creciente importancia.

Es bien conocida la posición del primer Adorno o de Marcuse respecto a las industrias culturales (la radio, el cine, la música grabada y transmitida), vistas como «un nuevo poder» y una nueva lógica estética al servicio del nazismo y el capitalismo en las sociedades industriales avanzadas — novedades técnicas cuyas nuevas posibilidades esperanzaban algo más a Brecht (1964) y a Benjamin (1989)—. 0 la desazón del primer Hoggart (2013) respecto a lo que escuchaban y leían «los obreros ingleses de hoy» (los de la posguerra) comparados con «los obreros de ayer», de comienzos de la industrialización, que estudiaba E. P. Thompson (1989). 0 la posición de los intelectuales italianos y la crítica fascista - a los que responde e interpela Gramsci en «Concepto de nacional-popular» (1986) - , que en 1930 se quejaban de que los periódicos publicaban anacrónicos folletines, encima extranjeros, en vez de sus obras literarias de vanguardia.

No se trata aquí de revisitar esta trayectoria histórica e intelectual, sino apenas tomar en cuenta, primero, que ya no es posible mantener la distinción tajante entre cultura urbana, industrias culturales, cultura de masas, sociedad de consumo y cultura 
popular. Que la complejidad productiva, la creación colectiva, la masividad en cuanto al alcance del público, etcétera, han devenido una de las condiciones y formas de lo popular, con todo lo que ello implica y significa, sin caer en los proverbiales determinismos apocalípticos o entusiasmos desmedidos e ingenuos, ya criticados por Eco (1968). No solo Hoggart (2013) descubrió formas propias, productivas y desviadas (en el sentido de usar y hacer cosas a su manera, en función de sus realidades e intereses, de las clases populares, a partir de la oferta cultural que les proponen las industrias, como advierten De Certeau [2000] y Hall [1984b]), sino que hasta el propio Adorno (1993) descubrió, hacia fines de los sesenta, las posibilidades de algunas industrias culturales (como el cine), así como evidencias del desempeño crítico de los lectores y telespectadores (Adorno, 1993; Ortiz, 2004). Más cerca de nuestra realidad, ya en los años cincuenta el escritor José María Arguedas comprendió la utilidad de los nuevos medios técnicos (el grabador, el disco, la radio) para la conservación, difusión y promoción de la cultura popular andina (García Liendo, 2016), frente a los embates de la cultura nacional letrada y la cultura internacional.

En segundo término, como han insistido distintos pensadores que se han ocupado de la recepción y la producción de sentido situada social e históricamente (Bajtín, Jauss, Iser, Chartier), es preciso atender a la capacidad de agencia y de respuesta de los lectores, escuchas y espectadores, que conservan y ejercen tareas de selección, decisión y reflexión (quizás no todo lo suficiente) pero, lejos de aceptar obedientemente todos los relatos y sentidos propuestos, y debido a sus historias y situaciones propias, inevitablemente adoptan distintas posiciones al respecto $\mathrm{y}$ «hacen otras cosas» con esas ofertas, no solo desviadas sino hasta opuestas (Ginzburg, Hall, De Certeau, los estudios de los grupos subalternos).

Por último, la centralidad insoslayable de las industrias culturales y la cultura de masas para cualquier acción, educación y política cultural, así como la dimensión de los poderes a los que nos enfrentamos, sus vigorosas y astutas estrategias, que tantas veces nos vencen y consiguen desanimar, no debe significar abandonar el escenario a esos poderes, sino confrontarlos en su propio terreno.

Así, teniendo en cuenta estas consideraciones, nos preguntamos ¿qué desafíos presentan las industrias culturales para una gestión que tiene como referente y fija su atención en la cultura popular mediatizada?

Visto desde este lugar, interesa subrayar cuando menos tres desafíos de gestión: a) investigación y conocimiento, b) capacidad de producción de una oferta alternativa competitiva, y c) legislación,

El primero implica investigar, conocer y llegar a un entendimiento cabal de las características y los modos de funcionamiento de los distintos campos e industrias culturales, de la cultura de masas, de los modos de funcionamiento de la esfera pública popular. Esto, que parece una perogrullada, supone remontar una dificultad histórica, 
superar un cierto habitus académico: el prejuicio, el desinterés y la desatención de la cultura letrada, los estudios académicos y las instituciones públicas hacia las industrias culturales y la cultura de masas (Eco, 1968), lo que ha desembocado en un sentido común o doxa con un pobre entendimiento de estas y, en última instancia, con una pobre teoría y una pobre capacidad de hacer al respecto.

Si bien en los últimos años se han desarrollado ámbitos específicos de investigación, de análisis crítico y de aprender a hacer (por ejemplo, en ciencias de la comunicación, en las facultades de arte, en la Universidad del Trabajo, en academias privadas), en las humanidades y en las ciencias sociales todavía campean el desdén, la falta de investigación y el poco conocimiento, todo lo cual luego se traduce y trasluce en la incapacidad de pensar e intervenir en el terreno de la cultura.

En segundo término, además de tener en cuenta la cuestión del consumo y la recepción productiva (que presenta sus propios desafíos, y de lo que nos ocuparemos en un instante), es preciso generar alternativas viables a la oferta dominante dentro del campo de las industrias culturales y la cultura de masas. En otras palabras, es preciso desarrollar la capacidad de competir y disputarles el dominio a las industrias culturales en su propio terreno.

Es decir, si estamos hartos del cine de los centros comerciales, de Netflix, de Cartoon Network, del catálogo de Alfaguara, es necesario generar opciones y plataformas propias iguales o más atractivas, con una oferta mayor y con productos de mejor calidad.

De más está decir, esto implica el desarrollo de un saber hacer, la formación de equipos, la asignación de importantes recursos y mucho más. El abaratamiento y la accesibilidad de algunos desarrollos tecnológicos juegan de nuestro lado.

Pese a lo imposible que esto parezca, existen sobrados ejemplos en el país, la región y el mundo de que es efectivamente posible, incluso en terrenos tan costosos como el cine, la tele, la radio, la prensa y la música, sobre todo de carácter público, pero también independiente. Hay numerosos ejemplos de iniciativas y emprendimientos culturales surgidos de la sociedad civil que han sabido y conseguido ganarse al público a pesar de competir con poderosas corporaciones. No obstante, debido a su relativo poderío (económico, político), el Estado está llamado a jugar un papel primordial, no solo en la regulación y la legislación, sino en la financiación y la producción en el ámbito de las industrias culturales (el cine, la radio y la TV, la industria editorial y musical, la ciudad como medio masivo [De Fusco, 1970]).

Tercero, las industrias culturales presentan para la gestión el desafío de la regulación y la legislación. Esto supone poner los derechos culturales de las personas por encima de los derechos de las corporaciones, asegurar el acceso a la cultura, y también límites y obstáculos a las prácticas abusivas, a la censura de hecho, a las manipulacio- 
nes de la propaganda, a la pobreza de las opciones. Parte de esto es lo que intentó atender la Ley de Medios, que no termina de empezar a regir.

Inversamente, es preciso legislar, construir institucionalidad y destinar recursos al uso de los medios y las industrias culturales propios (editorial, audiovisual, musical, etcétera) para garantizar el acceso a la cultura, tanto desde el punto de vista del acceso a los bienes culturales como de la posibilidad de expresión y producción alternativas.

\section{El consumo y la recepción productiva}

A los desafíos de gestión que presenta la necesidad de incursionar, intervenir y producir en el terreno de las industrias culturales y la cultura de masas - como tempranamente reclamaron Gramsci, Brecht, Benjamin o Eco-, los modos en que los usuarios seleccionan, acceden, utilizan y modifican los contenidos son un segundo foco de interés y punto de partida para la gestión.

Nuevamente, esto puede pensarse como dos momentos: a) el estudio del consumo y la recepción como aprendizaje, y b) el desarrollo de herramientas de apoyo para la selección y recepción provechosa, crítica y productiva.

En cuanto a lo primero, ello implica el desarrollo de estudios cuantitativos y sobre todo cualitativos de los procesos de recepción, para lo cual nos podemos servir del método etnográfico, el registro y la observación de instancias individuales y grupales de consumo, testimonios y relatos escritos, entrevistas, focus groups y el estudio de los productos realizados por los usuarios.

Lo segundo incluye - pero no se agota con ello- la capacitación de los usuarios en el manejo competente y crítico de las prácticas y los productos que las industrias culturales les ponen a disposición.

Aparte de aprender a desenvolverse de forma competente y crítica frente a determinado producto (libro, película, espectáculo), determinado campo (literatura, televisión, cine, teatro de carnaval) o plataforma (centro cultural, portal de internet), también es preciso contribuir a desarrollar la capacidad de buscar y acceder a archivos alternativos (llegado el caso, generarlos y gestionarlos), así como a desarrollar criterios y capacidades de selección, lo que implica aspectos técnicos (por ejemplo, acerca del lenguaje literario, musical o visual), pero también el conocimiento de distintas tradiciones, formas, movimientos, etcétera. Esto plantea concretar un objetivo largamente pendiente que es la inclusión - y mayor profundización- de estas materias (del alfabetismo audiovisual, por ejemplo, aunque no solamente) en la educación formal primaria y secundaria, en un mismo plano que idioma, literatura o dibujo.

Importante como es, la noción de formación de públicos capta una parte de esta cuestión, pero echa sombras sobre la otra mitad. La formación de públicos se apoya en 
la premisa de que un educador ya posee un conocimiento que necesita transferir al usuario para el mayor aprovechamiento y un mejor uso de un bien cultural, de una práctica cultural, pero esto es así solo hasta cierto punto. Por el contrario, uno de los desafíos que presenta el consumo para la gestión es justamente el de conocer y aprender acerca de prácticas y formas de uso por lo general poco conocidas y poco estudiadas por los educadores, en general formados en la alta cultura pero con escaso o nulo conocimiento (teórico, sistemático) de la cultura popular o la cultura de masas (internet, los graffiti, el hip hop, la cumbia, el carnaval, el rock, las películas y series de TV, y toda una larga serie de consumos y prácticas culturales populares).

Así, tanto como enseñar a los niños y jóvenes a usar internet, es necesario también conocer qué y cómo lo hacen: aprender de ellos.

De la misma manera, en un mundo copado por la pantalla, si bien es preciso enseñar a ver la tele, a ver cine, a escuchar música (lo cual significa aportar herramientas de lectura, de análisis, de crítica, de apreciación, de los que en general carecen), deviene igualmente necesario aprender de los usuarios acerca de sus modos y criterios de navegación, de selección, de valoración —-sus reflexiones, razones y sentires respecto a sus opciones culturales-, qué leen («qué ves cuando me ves»), ven o escuchan (qué sentidos producen), y qué hacen los usuarios con todo ello.

Esto servirá no solo como insumo para una mejor gestión (en el sentido de aportar tareas de apoyo y desarrollo), sino que resultará en un enriquecimiento teórico y cultural del propio educador-formador (del gestor, de las autoridades de la cultura, del legislador) y en la transformación del modelo cultural y del proyecto cultural que orienta la política pública.

\section{La producción de los transculturadores populares}

Las industrias culturales, la cultura de masas e incluso la recepción productiva no terminan de resolver el problema.

Resta pensar en los desafíos que presentan para la gestión las producciones desde abajo más elaboradas, por obra de los transculturadores populares (que también intervienen en la esfera pública popular); producciones que de hecho pueden llegar a significar operaciones y procesos colectivos, complejos, como en el caso del carnaval, el mercado de contenidos pirateados, los poetas, cantantes y actores callejeros, las radios comunitarias, los centros culturales vecinales, la movida del graffiti, o distintas plataformas y productos difundidos por internet (portales, blogs, sitios de intercambio), devenidos en verdaderas industrias culturales alternativas. 
Llegados a este punto volvemos al problema que intentamos ilustrar, en el comienzo, con el caso del carnaval, aunque en verdad hay más preguntas y dilemas que respuestas.

La gestión puede adquirir el sentido de control, de censura, de regulación, de aprovechamiento económico, de ingeniería cultural. Y, por cierto, no faltarán los intentos de capturar y manipular en beneficio propio estas producciones por parte de los actores económicos, políticos y de diversa índole, lo cual es un momento de una dialéctica de la cultura. 0 la gestión puede significar construir en relación y disposición de aprendizaje y apoyo a este otro universo cultural, que por definición será, como decíamos, contextual, relacional, procesual, heterogéneo, contradictorio.

También puede significar confrontar e intentar dar una respuesta a la serie de dilemas y contradicciones que presenta la cultura popular, que a veces enfrenta argumentaciones en uno y otro sentido, o cuya resolución es política y significa tomar partido.

Así, aun cuando hablemos del carnaval, de la cumbia, del graffiti o de las plataformas piratas, habrá que lidiar con aspectos éticos, legales, políticos y estéticos: ¿Cuáles son los límites a la libertad de expresión, en el ámbito de la esfera pública popular? ¿Qué ocurre cuando la cultura popular se asemeja demasiado a la cultura oficial? ¿Cómo defender la cultura popular de la coerción y la manipulación política y económica? La profesionalización, la incorporación de tecnología y de know how, o la mejora en la complejidad, sofisticación y calidad de la cultura popular, ¿juegan a favor o en contra de la democratización, o las dos cosas a la vez?

Debido al carácter informal y, por definición, desalineado de la cultura popular, muchas veces contracultural y antisistémica, ello implicará, asimismo, pensar en criterios de uso justo y razonable: ¿En qué casos una estación de radio puede hacer uso de una frecuencia? ¿En qué casos está bien, y en cuáles no, pintar o blanquear un muro? El Concurso Oficial del carnaval ¿debe ser o no la visa para actuar en los tablados? ¿Hay derecho a subir o a bajar contenidos de internet para acceder a la cultura de calidad como forma de sortear una oferta controlada y censurada por las grandes corporaciones? Preguntas de este tipo requieren una discusión y una respuesta, y sobre todo un hacer consecuente, una gestión. 


\section{La gestión de la cultura popular, transformación cultural y derechos humanos}

Para resumir y concluir: la gestión de la cultura popular presenta varios tipos de desafíos.

Por la ambigüedad del término gestión cultural, primero, la necesidad de desmitificar su neutralidad y pensarla siempre situada, motivada, orientada. Esto se agrava y complejiza todavía más al tratarse de la cultura popular, una producción en situación de subalternidad, es decir, en relación con distintas formas de poder (económico, político, cultural, social, etcétera).

Segundo, por la propia complejidad que presentan el concepto y la realidad de la cultura popular (contra la ilusión positiva y la metafísica de la presencia), que hemos tratado de capturar mediante el concepto de esfera pública popular, tributario de lo popular de Bajtín y Gramsci, de la noción de esfera pública de Habermas y hasta de campo de Bourdieu (al pensarlo como sistema de relaciones, reglas propias, reconfiguraciones en el tiempo).

Tercero, la necesidad de pensar lo popular en distintos planos: como mediado y masificado (Martín Barbero), como consumo, respuesta creativa y usos productivos (visto desde la recepción) y, finalmente, como prácticas culturales y producciones alternativas más elaboradas y complejas.

Por último, interesarnos por la gestión de la cultura popular solo tiene sentido si está orientada hacia la democratización y la transformación social, hacia la promoción y realización de los derechos humanos, en la creencia de que el terreno de la cultura también juega su parte y que en la cultura popular están cuando menos la mitad de las respuestas, capacidades y energías.

Termino, por tanto, con un epígrafe del poeta español Blas Otero, quien citando en el poema «Escrito con lluvia» a un colega suyo, Augusto Ferrán, reconocía: «[...] he puesto unos cuantos cantares del pueblo [...], para estar seguro al menos de que hay algo bueno en este libro».

\section{Referencias bibliográficas}

Adorno, T. (1993). «Tiempo libre». En Consignas. Buenos Aires: Amorrortu Editores. AlthuSSER, L. (1988). Ideología y aparatos ideológicos del Estad: Freud y Lacan. Nueva Visión: Buenos Aires.

BAjTín, M. (1987). La cultura popular en la Edad Media y el Renacimiento. Buenos Aires: Alianza.

BAJTín, M. (1993). Problemas de la poética de Dostoievski. Buenos Aires: FCE. 
BENJAMIN, W. (1989). «La obra de arte en la época de su reproductibilidad técnica». En Discursos interrumpidos. Buenos Aires: Taurus.

BENJAMIN, W. (2004). El autor como productor. México: Itaca.

Bourdieu, P. (1980). Campo de poder, campo intelectual. Buenos Aires: MontressorJungla simbólica.

BRECHT, B. (1964). «The radio as an apparatus of communication». En Brecht on theatre: The development of an aesthetic. New York: Hill \& Wang.

DE CERTEAU, M. (2000). La invención de lo cotidiano: Las artes de hacer. México: Universidad Iberoamericana.

DE Fusco, R. (1970). Arquitectura como «mass medium»: Notas para una semiología arquitectónica. Barcelona: Anagrama.

DERRIDA, J. (1998). «La différance». En Márgenes de la filosofía. Madrid: Cátedra.

ECo, U. (1968). Apocalípticos e integrados. Buenos Aires: Lumen.

GARCía CANCLINI, N. (1981). Las culturas populares en el capitalismo. Buenos Aires: Nueva Imagen.

GARCÍA CANCLINI, N. (1986). ;De qué estamos hablando cuando hablamos de lo popular. Montevideo: CLAEH. (Materiales para el debate contemporáneo, 7).

GARCÍA LIENDO, J. (2016). El intelectual y la cultura de masas. Indiana: Purdue University. GramsCi, A. (1986). Cuadernos de la cárcel (Vol. 6). México: Ediciones Era.

HABERMAS, J. (1981). Historia y crítica de la opinión pública. La transformación estructural de la vida pública. Barcelona: Gustavo Gili.

HALl, S. (1984a). «Notas sobre la deconstrucción de lo popular». En R. Samuel (ed), Historia popular y teoría socialista (pp. 1-10). Barcelona: Crítica.

HALL, S. (1984b). «Encoding/decoding». En S. During (ed.), The cultural studies reader. Routledge: New York.

HogGart, R. (2013). La cultura obrera en la sociedad de masas. Buenos Aires: Siglo XXI.

HorkHEIMER, M. (1973). Crítica de la razón instrumental. Buenos Aires: Sur.

Horkheimer, M. y Adorno, T. (1998). Dialéctica de la Ilustración. Madrid: Trotta.

Martín BARBERo, J. (1987). De los medios a las mediaciones. México: Ediciones Gustavo Gili.

ORTIZ, R. (2004). «La Escuela de Frankfurt y la cuestión de la cultura». En Taquigrafiando lo social. Buenos Aires: Siglo XXI.

RAMA, A. (1982). Transculturación narrativa en América Latina. México: Siglo XXI.

ScotT, I. (2000). Discursos ocultos: Los dominados y el arte de la resistencia. México: Era.

Thompson, E. P. (1989). La formación de la clase obrera en Inglaterra. Barcelona: Crítica/Grijalbo.

Thompson, J. B. (1996). «La teoría de la esfera pública». Voces y culturas, 10, 1-12. 


\section{Bibliografía consultada}

Alabarces, P. (2008). «Un destino sudamericano: La invención de los estudios sobre cultura popular en la Argentina». En P. AlABARCES y M. RODRíguEz (comps.), Resistencias y mediaciones: Estudios sobre cultura popular. Buenos Aires: Paidós.

AlABARCES, P. (2012). «Transculturas pospopulares: El retorno de las culturas populares en las ciencias sociales latinoamericanas» Cultura y representaciones sociales, 7(13): 7-39.

AlABARCES, P. Y AÑón, V. (2016). «Subalternidad, pos-decolonialidad y cultura popular: nuevas navegaciones en tiempos nacional-populares». Versión. Estudios de comunicación y Política, 37, 13-22.

BADIoU, A. (2015). «Veinticuatro notas sobre los usos de la palabra "pueblo"». En ¿Qué es un pueblo? Buenos Aires: Eterna Cadencia.

BAJTíN, M. (1999). «El problema de los géneros discursivos». En Estética de la creación verbal. México: Siglo XXI.

Benjamin, W. (2010). El París de Baudelaire. Buenos Aires: Eterna Cadencia.

Bourdieu, P. (1990). Sociología y cultura. México: Grijalbo.

Chakrabarty, D. (2010). «Una pequeña historia de los estudios subalternos». En P. SANDOVAL (comp.), Repensando la subalternidad: Miradas críticas desde/sobre América Latina (pp. 25-52). Popayán: Envión. Recuperado de http://www.qellca.com/sites/default/files/repensando_la_subalternidad._mirad as_criticas_sobre_america_latina.pdf\#page $=29$.

CHARTIER, R. (1999). «Introducción a una historia de las prácticas de lectura en la era moderna (s. XVI-XVIII)». En El mundo como representación. Barcelona: Gedisa.

Del Sarto, A.; Ríos, A. y Trigo, A. (eds.) (2005). The Latin American cultural studies reader. Durham: Duke University Press.

Ford, A. (1985). «Cultura dominante y cultura popular». En A. ForD, J. B. RIVERA y E. Romano, Medios de comunicación y cultura popular. Buenos Aires: Legasa.

García CANClini, N. (1990). «La sociología de la cultura de Pierre Bourdieu». En P. Bourdieu, Sociología y cultura. México: Grijalbo.

García CANCLINI, N. (1995). Consumidores y ciudadanos. México: Grijalbo.

GARCía CANCLini, N. (ed.). (2015). Hacia una antropología de los lectores. México: Ariel.

GiNZBURG, C. (1999). El queso y los gusanos. Barcelona: Muchnik Editores.

Grimson, A. y VARELA, M. (2002). «Culturas populares, recepción y política. Genealogía de los estudios de comunicación y cultura en Argentina», en D. MATo (comp.), Estudios y otras prácticas intelectuales en cultura y poder. Caracas: CLACSO.

HALL, S. (2000). «El surgimiento de los estudios culturales y la crisis de las Humanidades». En E. RestrePo, C. WAlsh y V. Vich (eds), Stuart Hall: Sin garantías. Trayecto- 
rias y problemáticas en estudios culturales. Lima: Instituto de estudios sociales y culturales Pensar.

HobSBAWM, E. (1983). «Notas para el estudio de las clases subalternas». En Marxismo e historia social. México: Instituto de Ciencias de la Universidad Autónoma de Puebla.

ISER, W. (1989). «El proceso de lectura». En R. WARNING (eds), Estética de la recepción. Madrid: Visor.

JAUSS, H. R. (1987). «Historia de la literatura como una provocación a la ciencia literaria». En D. RALl (comp.), En busca del texto: Teoría de la recepción literaria. México: UNAM.

LACLAU, E. (1978). Política e ideología en la teoría marxista. Madrid: Siglo XXI.

LAClau, E. y MoufFe, C. (1987). Hegemonía y estrategia socialista: Hacia una política democrática radical. Madrid: Siglo XXI.

LiEnHARD, M. (1994). «Oralidad». Revista de Crítica Literaria Latinoamericana. 20(40), 371-374.

LIENHARD, M. (2000). «Voces marginadas y poder discursivo en América Latina». Revista Iberoamerican, 64(193): 785-798.

Lyons, M. (1998). «Los nuevos lectores del siglo XIX: mujeres, niños, obreros». En G. CAVAllo y R. Chartier (eds.), Historia de la lectura en el mundo occidental. Madrid: Taurus.

MARCuSE, H. (1964). One-dimensiomal man: Studies in the Ideology of advanced industrial society. Boston: Beacon Press.

Mattelart, A. y Neveu, E. (2002). Los Cultural studies: Hacia una domesticación del pensamiento salvaje. La Plata: Facultad de Periodismo y Comunicación Social.

MatTElART, A. y Neveu, E. (2004). «Los años de Birminghan (1964-1980): La primavera de los estudios culturales». En Introducción a los estudios culturales. Barcelona: Paidós.

MíGuEZ, D. y SEMÁN, P. (2006). «Diversidad y recurrencia en las culturas populares actuales». En D. MíGUEZ y P. SEMÁN (eds.), Entre santos cumbias y piquetes: Las culturas populares en la Argentina reciente. Buenos Aires: Biblos.

Negt, O. y KLUge, A. (1993). Public sphere and experience: Towards an analysis of the bourgeois and proletarian public spheres. Minneapolis: University of Minnesota Press.

RAMA, A. (1984). La ciudad letrada. Hanover: Ediciones del Norte.

RAMA, A. (1998). Los gauchipolíticos rioplatenses. Montevideo: Arca.

RANCIÈRE, J. (2015). «El inhallable populismo». En ¿Qué es un pueblo? Buenos Aires: Eterna Cadencia. 
REMEDI, G. (1992). «Esfera pública popular y transculturadores populares». En H. VIDAL (ed.), Hermenéuticas de lo popular. Minneapolis: Institute for the Study of Ideologies and Literatures.(Literatura y Derechos Humanos, 9).

REMEDI, G. (2004). «The production of local public spheres: Community radio stations».

En A. Del Sarto, A. Trigo y A. Rios, (eds.), The Latin American cultural studies reader. Durham: Duke University Press.

REMEDI, G. (2005). «Las bases estéticas de la ciudadanía». Aisthesis 38, 57-72.

REMEDI, G. (2009). «Teatro de frontera/espacios contaminados: Argumentos desde la transmodernidad». En R. MiRZA (ed.), Teatro, memoria, identidad. Montevideo: FHCE.

REMEDI, G. (2014). «El apagón cultural y la música tropical uruguaya: Pailas, güiros y trompetas en el cuarto de atrás de la Atenas del Plata». Studies in Latin American Popular Culture, 32, 3-30.

REMEDI, G. (2015). El teatro fuera de los teatros: Reflexiones críticas desde el archipiélago teatral. Montevideo: CSIC.

SARLO, B. (1985). El imperio de los sentimientos. Buenos Aires: Catálogo Editora.

SEMÁN, P. y VILA, P. (2011). Cumbia: Nación, etnia y género en América Latina. Buenos Aires: Gorla.

VIDAL, H. (1987). Poética de la población marginal: Fundamentos materialistas para una historiografía estética. Minneapolis: Institute for the Study of Ideologies and Literatures.

VIDAL, H. (1992). «La noción de otredad en el marco de las culturas nacionales». En H. VIDAL (ed.), Hermenéuticas de lo popular. Minneapolis: Institute for the Study of Ideologies and Literatures.(Literatura y Derechos Humanos, 9).

Williams, R. (1989). «Culture Is Ordinary». En R. GALE (ed.), Resources of hope, democracy, socialism. London: Verso.

Williams, R. (1994). Sociología de la cultura. Barcelona: Paidós.

WiLliams, R. (1997). Marxismo y literatura. Barcelona: Península.

WiLliams, R. (2001). Cultura y sociedad. Buenos Aires: Nueva Visión.

WiLliams, R. (2003). La larga revolución. Buenos Aires: Nueva Visión.

WRIGHT, S. (1998). «La politización de "la cultura"». Anthropology Today, 14(1). 